\title{
Breaking the Stringent Trade-off between Mode area and NA for Efficient High-power Fiber Lasers around $2 \mu \mathrm{m}$
}

\author{
Deepak Jain, Jayanta K. Sahu, and Simon Fleming
}

\begin{abstract}
We propose a novel approach of exploiting the LP: mode in ultra-high NA confined-doped M-type fibers to ensure effective single-mode operation, thereby breaking the trade-off between mode-area scaling and ultra-high NA. This novel approach opens the door to highly rare-earth doped fibers suitable for power scaling applications. Therefore enabling, simultaneously scaling of power and slope efficiency of fiber lasers.
\end{abstract}

Index Terms - Large mode area fibers, High power fiber lasers, Non-linear effects, and Modal-Instability.

\section{INTRODUCTION}

$\mathrm{N}$ on-linear effects (such as stimulated Raman scattering, stimulated Brillouin scattering, four wave mixing, selfphase modulation, and cross-phase modulation) have been used in optical fibers for generation of narrow and broadband spectrums [1]. In-order to avoid the detrimental non-linear effects in rare-earth-doped narrow-linewidth high-power fiber lasers, a large-core diameter fiber is an obvious choice to decrease the power density [1]. However, a large-core leads to the propagation of higher-order-modes (HOMs), and therefore poor beam quality [2]. There are numerous fiber designs offering large core diameter while suppressing the HOMs, such as low numerical aperture (NA) step-index fibers (SIF) [3], Bragg fibers [4], photonic bandgap fibers (PBGFs) [5], singletrench fibers (STF) [6-8], chirally coupled core fibers (CCC) [9], large pitch fibers (LPFs) [10], and multi-trench fibers [11] etc. A large number of high-power lasers with good beam quality have been demonstrated using these fibers around $1 \mu \mathrm{m}$. However, it is important to keep in mind that the refractive index of the core of these fiber designs has to be either the same as or slightly higher than, that of the cladding, and this constraints the doping level of the rare-earth (RE) and codopants ions required to prevent the clustering of the RE-ions. Thulium-doped fiber lasers emitting around $2 \mu \mathrm{m}$ require doping with a high level of $\mathrm{Tm}^{3+}$ ions in order to exploit the 2:1 cross relaxation [12]. An optimum exploitation of the 2:1 cross relaxation can give a laser slope efficiency close to the $80 \%$ theoretical level [12]. Several laser demonstrations have been

Manuscript received April X, 2020; revised YYYY X, 2016 and YYYY X, 2016; accepted YYYY X, 2016. Current version published YYYY X, 2016. The work is supported by the "The University of Sydney Research Fellowship"

D. Jain and S. Fleming works at the Institute of Photonics and Optical Sciences, School of Physics and Sydney Nano Institute, The University of Sydney, NSW, SO17 1BJ, Australia (e-mail: deepakjain9060@gmail.com, achieved with efficiencies exceeding $70 \%$, however this requires more than $2 \mathrm{wt} \%$ of $\mathrm{Tm}^{3+}$ ions along with significant levels of $\mathrm{Al}^{3+}$ ions [13-14]. Recently, Tumminelli et al. demonstrated a record $74.5 \%$ slope efficiency with respect to absorbed pump power using an $8.5 \mathrm{wt} \% \mathrm{Tm}_{2} \mathrm{O}_{3}$ doped fiber [15]. Therefore, power scaling with good efficiency at $2 \mu \mathrm{m}$ comes with the additional challenge of maintaining singlemode operation of a large mode area with high NA fiber. This explains the scarcity of efficient near-diffraction limited beam $\left(\mathrm{M}^{2}<1.1\right)$ high-power thulium doped fiber laser sources [16].

There are only two existing solutions for this problem, the first is to use the HOM approach in a heavily multi-moded fiber [17] and the second is to use a pedestal fiber design [18]. In the HOM approach, the careful excitation of a particular mode such as $\mathrm{LP}_{0 \mathrm{~m}}(\mathrm{~m}>1)$ requires the conversion of the $\mathrm{LP}_{01}$ mode to the $\mathrm{LP}_{0 \mathrm{~m}}$ mode at the input and re-conversion of the $\mathrm{LP}_{0 \mathrm{~m}}$ mode to the $\mathrm{LP}_{01}$ mode at the output, using long period gratings (LPGs) [17]. During re-conversion, the peak-power can be high enough to cause non-linearity induced changes leading to severe mode coupling in the LPG [19]. Therefore, this is not a reliable solution. The pedestal approach requires an additional heavily multi-moded, large diameter, passive cladding surrounding the doped core, with a smaller NA than the core, which increases the fabrication challenges and cost. It can effectively reduce the core's NA, which helps to reduce the number of guided modes in the core. Power levels of $\sim 170 \mathrm{~W}$ with $\mathrm{M}^{2}$ value of 1.02/1.03 from a $20 \mu \mathrm{m}$ core with $65 \mu \mathrm{m}$ pedestal with an estimated efficiency of $\sim 58 \%$ [20], and $\sim 567 \mathrm{~W}$ with a high $\mathrm{M}^{2}$ value of $\sim 2.6$ from a $25 \mu \mathrm{m}$ core with $40 \mu \mathrm{m}$ pedestal with an efficiency of $~ 50 \%$ [21] have been demonstrated. Both fibers have nearly the same core Dn $\sim 0.004$ with respect to the pedestal and the pedestal Dn $\sim 0.017$ with respect to the cladding [22]. Recently Hemming et al. demonstrated $\sim 440 \mathrm{~W}$ output power at $\sim 1.95$ $\mu \mathrm{m}$ using pedestal fiber design [23]. Authors claim a robust single-mode behavior and the details to ensure a single-mode operation are not available in public domain [23]. Kuhn et al. demonstrated a modal-content study of the pedestal fibers showing nearly an $82 \%$ fraction for the $\mathrm{TEM}_{00}$ mode [24]. It is obvious that the pedestal cladding is heavily multi-moded,

deepak.jain@sydney.edu.au, and simon.fleming@sydney.edu.au). J. Sahu works at the Optoelectronics Research Center, University of Southampton, Southampton, SO17 1BJ, UK (e-mail: iks@orc.soton.ac.uk).

Color versions of one or more of the figures in this paper are available online athttp://ieeexplore.ieee.org. Digital Object Identifier 
supporting numerous modes such as $\mathrm{LP}_{02}, \mathrm{LP}_{12}, \mathrm{LP}_{22}$ etc. which have strong overlap with the doped region of the core. Therefore, pedestal design might not be an ideal design for ensuring robust single mode operation at high power output levels, like any other non-intrinsic single-mode fiber design. In this paper, we demonstrate that the $\mathrm{LP}_{02}$ modes in a large-core, high-NA M-type fiber with confined doping, which can offer effective single mode operation. This will be helpful for power scaling of efficient RE-doped fiber lasers with high NA. The refractive-index profile of the M-type fiber resembles to the letter " $\mathrm{M}$ " that is why this is known as M-type fiber [25-27]. Mtype can offer unusual properties such as enhanced pump absorption efficiency [25], flat-field fundamental mode [2830], different guidance to the different modes so that the first few modes can be confined in a ring and the other modes can be confined in the core [31]. This allows easy excitation of the $\mathrm{LP}_{02}$ mode in the core while confining the lower order modes (LOMs) such as $\mathrm{LP}_{01}, \mathrm{LP}_{11}$, and $\mathrm{LP}_{21}$ etc. to the ring. Recently Aleshkina et al., for the first time, demonstrated the exploitation of the anomalous dispersion profile of the $\mathrm{LP}_{02}$ and $\mathrm{LP}_{03}$ mode for non-linear applications using M-type fibers [31-34]. Thereafter, Jain et al. also proposed the exploitation of the anomalous dispersion profile of the $\mathrm{LP}_{02}$ mode for mid infrared supercontinuum generation [35]. In this paper, to the best of our knowledge, this is the first proposal of the exploitation of the $\mathrm{LP}_{02}$ mode of M-type fiber for mode-area scaling in ultra-high NA fibers.

\section{WORKING PRINCIPLE}

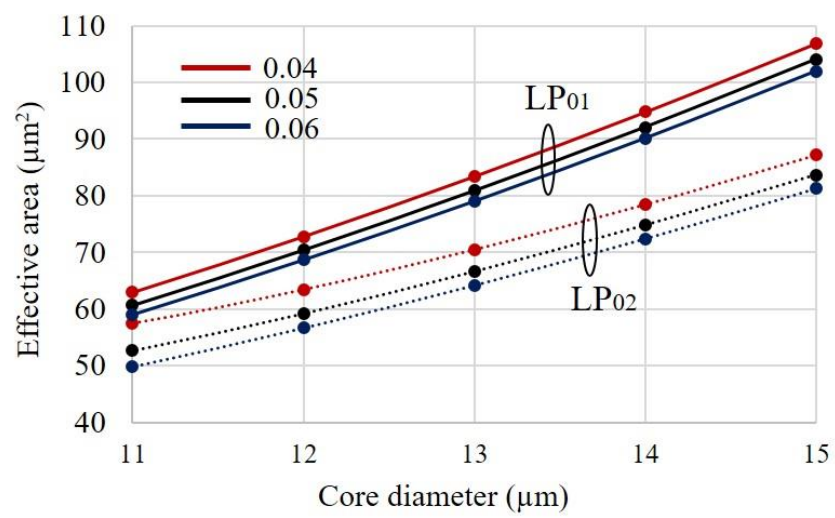

Fig. 1 Effective area of the $\mathrm{LP}_{01}$ and $\mathrm{LP}_{02}$ modes with respect to core diameter at $2 \mu \mathrm{m}$ wavelength, for different NA's of step-index fibers.

First let us consider standard step index fibers. Figure 1 shows the calculated effective area of the $\mathrm{LP}_{01}$ and $\mathrm{LP}_{02}$ modes for varying core diameters of step-index fibers with different refractive index between core and cladding $(\triangle \mathrm{n})$ at $2 \mu \mathrm{m}$ wavelength. The effective area of both $\mathrm{LP}_{01}$ and $\mathrm{LP}_{02}$ modes decreases with increasing NA, demonstrating the impact of the stronger guidance. It is important to note that the effective area of the $\mathrm{LP}_{02}$ mode is smaller than the $\mathrm{LP}_{01}$ mode for well-guided $\mathrm{LP}_{02}$ modes. Moreover, the difference of the effective area increases from $\sim 10 \%$ to $\sim 15 \%$ with increasing core diameter from 11 to $15 \mu \mathrm{m}$. There are several important things to note, first for the same core diameter there is potential to exploit the
$\mathrm{LP}_{02}$ mode rather than the $\mathrm{LP}_{01}$ mode for non-linear applications thanks to its shorter zero dispersion wavelength and anomalous dispersion profile [31, 35-36]. The second consideration about the $\mathrm{LP}_{02}$ mode is the possibility to exploit this behavior to avoid the non-linear effects. Whilst this might appear contradictory, it can actually work. For a larger core such as $15 \mu \mathrm{m}$ diameter, the effective area for the $\mathrm{LP}_{02}$ mode is larger than the effective area of the $\mathrm{LP}_{01}$ mode for $13 \mu \mathrm{m}$ core diameter. This is also evident from the normalized frequency $\mathrm{V}$ number, the cut-off value for the $\mathrm{LP}_{12}$ mode is 5.520 , whilst it is 2.405 for the $\mathrm{LP}_{11}$ mode. Therefore, for the same NA the $\mathrm{LP}_{02}$ mode can afford a $\sim 2.3$ times larger core than the $\mathrm{LP}_{01}$ without guiding any HOMs. Similarly, for the same core-diameter the $\mathrm{LP}_{02}$ mode can afford $\sim 2.3$ times higher NA. This allows breaking the stringent tradeoff between mode-area scaling and NA.

However, this approach comes at a cost of already guiding three lower-order-modes (LOMs) $\mathrm{LP}_{01}, \mathrm{LP}_{11}$, and $\mathrm{LP}_{21}$. Therefore, a technique is required to ensure that only the $\mathrm{LP}_{02}$ mode is excited without exciting these LOMs. The current solution is to use LPGs; however, as stated above, LPG are highly sensitivity to non-linear effects at high peak powers [19]. Therefore, we consider the alternative solution of using M-type fibers. Figure 2 shows a schematic of a typical M-type fiber together with fiber parameters such as core-diameter (D), ring thickness ( $t$ ), refractive index difference between ring and cladding (DN), and refractive index difference dip from ring to internal core (Dn). M-type fibers allow the $\mathrm{LP}_{02}$ mode to be core-confined, while keeping other LOMs confined to the ring. This allows the effective use of the $\mathrm{LP}_{02}$ mode. In this study we use active $\mathrm{M}$ type fiber, assuming the inner-core of the fiber to be doped with RE-ions and ring to be doped with passive index-raising dopants.

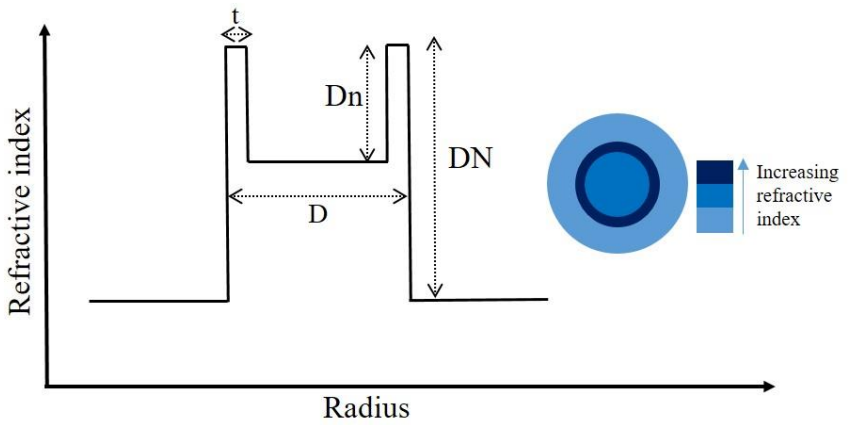

Figure 2 Refractive index profile of the M-type fiber with characteristic parameters core diameter (D), ring thickness (t), DN (refractive index difference between ring and cladding), and refractive index dip (Dn). The inset shows the 2D cross-section of an M-type fiber.

It is extremely interesting to compare the electric field intensity distributions of the $\mathrm{LP}_{02}$ modes in SIF and M-type fibers. Figure 3 (a) shows the calculated power fraction of the central $\left(\mathrm{P}_{\mathrm{LPO} 2}(\mathrm{c})\right.$ $=\mathrm{Pc} /(\mathrm{Pc}+\mathrm{Pa}))$ and annular $\left(\mathrm{P}_{\mathrm{LP} 02}(\mathrm{a})=\mathrm{Pa} /(\mathrm{Pc}+\mathrm{Pa})\right)$ regions of the $\mathrm{LP}_{02}$ mode for a $12 \mu \mathrm{m}$ core diameter SIF with different $\Delta \mathrm{ns}$ at $2 \mu \mathrm{m}$ wavelength, where Pc is the power in central region and $\mathrm{Pa}$ is the power in annular region. The central region has higher intensity, but the surface area of the annular region is higher, therefore the power fraction in the annular region is higher than the central region. Figure 3(b-f) shows the calculated $\mathrm{P}_{\mathrm{LP} 02}(\mathrm{c})$ 


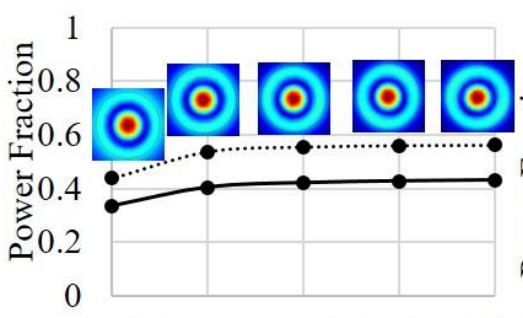

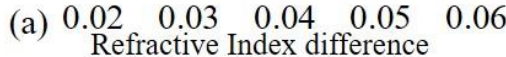

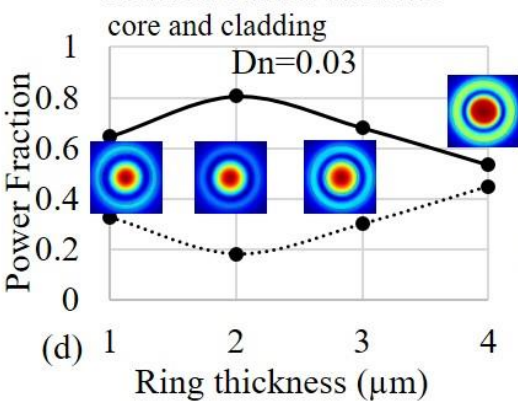

Ring thickness $(\mu \mathrm{m})$
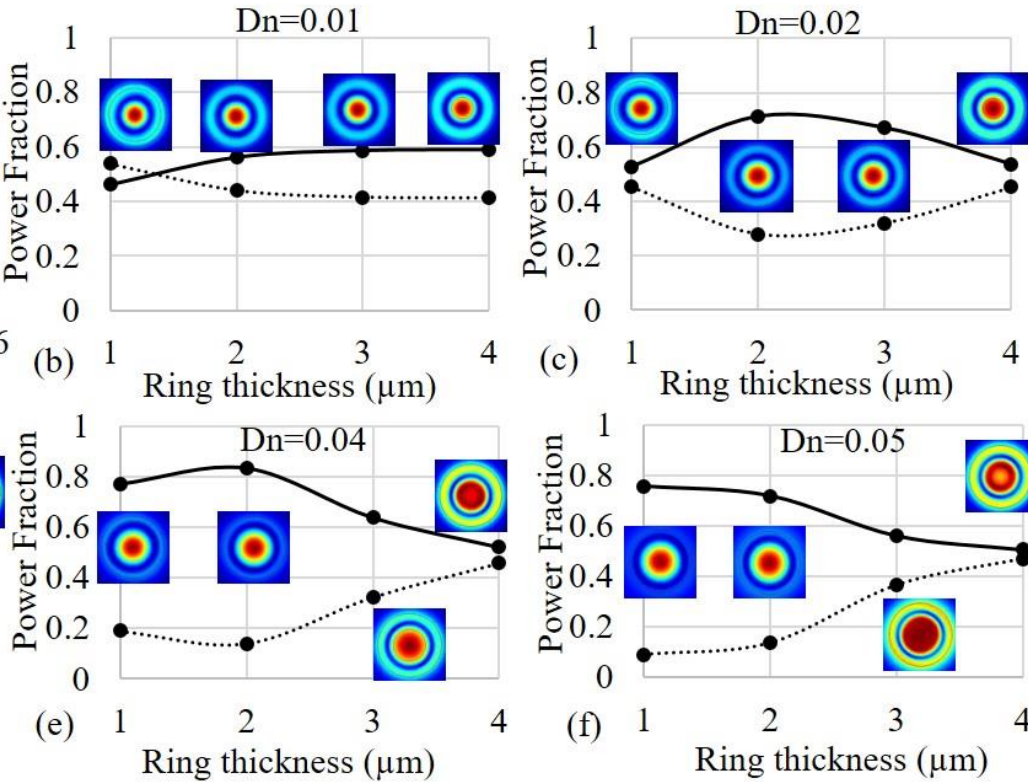

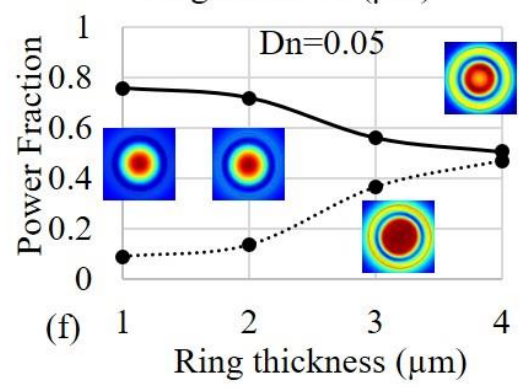

Figure 3. Power fraction in the central and annular regions of the $\mathrm{LP} 02$ mode (a) step-index fiber with core diameter $12 \mu \mathrm{m}$ with varying refractive index difference between core and cladding (b-f) M-type fiber with core diameter $12 \mu \mathrm{m}$ with varying $\mathrm{Dn}=0.01,0.02,0.03,0.04,0.05$, thickness ring $(\mathrm{t}=1,2,3,4 \mu \mathrm{m})$, and $\mathrm{DN}=0.06$. The operational wavelength is $2 \mu \mathrm{m}$. Solid curve shows power in central region and dotted curve shows power in annular region. Inset shows the electric field intensity distribution of each mode.

and $\mathrm{P}_{\mathrm{LP} 02}(\mathrm{a})$ of the $\mathrm{LP}_{02}$ mode for a $12 \mu \mathrm{m}$ core diameter M-type fiber with $\mathrm{DN}=0.06$ for varying ring thickness $(\mathrm{t}=1,2,3,4 \mu \mathrm{m})$ for different central refractive index dip $(\mathrm{Dn}=0.01,0.02,0.03$, 0.04, and 0.05). A quick comparison of Fig. 3(a) with Fig. 3(bf) shows that more power resides in the central region compared to the annular region in case of the M-type fibers. This effect increases with increasing Dn from 0.01 to 0.03 and then remains nearly constant. Other than Dn, ring thickness dramatically impacts the power distribution. The maxima values of the power fraction difference between the central and annular region vary between 1 to $3 \mu \mathrm{m}$ ring thicknesses.

Other than the power distribution, the surface area of the central region in the case of the M-type fiber is also larger than the SIF. For larger ring thickness, such as $\mathrm{t}=4 \mu \mathrm{m}$, the central region's electric field intensity profile moves from Gaussian to flat-top for the higher values of the Dn, as the effective refractive index of the mode approaches close to the central dip's refractive index. This impacts the field distribution dramatically and results in nearly the same power in both regions. It is interesting to note that it is possible to engineer out the power distribution in different regions of the $\mathrm{LP}_{02}$ mode by varying the central refractive index dip and ring thickness. The modes in the central-dip region see hybrid guidance, first due to the Fresnellike reflection from the high-index ring between the central core and cladding similar to the Bragg fibers, and second due to the total-internal reflection (TIR) like guidance between the central core and cladding $[4,31]$. This hybrid guidance changes the electric field distribution, as observed in Fig. 3 for the $\mathrm{LP}_{02}$ mode. For appropriate Dn and t, it is possible to confine more than $80 \%$ of the power in the central region, for instance with $\mathrm{Dn}=0.03$ to 0.04 and $\mathrm{t}=2 \mu \mathrm{m}$. At the exit end, it is expected that central region will carry most of the power and therefore, no conversion to the $\mathrm{LP}_{01}$ mode is required.

\section{MODE AREA SCALING.}

In order to exploit the $\mathrm{LP}_{02}$ mode, it is important to ensure effective single mode operation. In this section, we consider three sets of studies with different $\mathrm{DN}$ and $\mathrm{Dn}$ : $\mathrm{DN}=0.06$ and $\mathrm{Dn}=0.03$ and $\mathrm{DN}=0.04$ and $\mathrm{Dn}=0.02$. A refractive index difference (Dn) of 0.02 to 0.03 is enough to accommodate sufficient $\mathrm{Tm}^{3+}$ and $\mathrm{Al}^{3+}$ ions to exploit the $2: 1$ cross relaxation, in order to generate a high slope efficiency.

Numerical simulations have been executed using commercially available Finite Element Method (FEM) based COMSOL Multiphysics 5.3 software. An isotropic perfectly matched layer (PML) was used to truncate the infinite cladding. During calculations, all polarizations and orientations were considered. In order to make fair claims, we always quote the least value of the losses and the highest value of the power fraction in the core for unwanted modes, considering all possible polarizations and orientations of the unwanted modes.

\section{(a) $\mathrm{DN}=0.06$ and $\mathrm{Dn}=0.03$}

Figure 4 shows the dispersion profiles of the different modes and power fraction overlap with central doped core $\left(\mathrm{P}_{\mathrm{CDC}}\right)$ for varying core diameters for fixed $\mathrm{DN}=0.06, \mathrm{Dn}=0.03, \lambda=2 \mu \mathrm{m}$, and coiled at a bend diameter of $5 \mathrm{~cm}$. It is important to note that, there are crossings between dispersion curves (i.e. $\mathrm{LP}_{02}$ curve crosses $\mathrm{LP}_{31}$ and $\mathrm{LP}_{41}$ curves), these are resonant couplings. This a common feature of M-type fibers and has been reported earlier [34-35].

We did not observe any considerable losses for the $\mathrm{LP}_{02}$ mode for the fiber parameters in this study, and so a loss of more than $10 \mathrm{~dB} / \mathrm{m}$ for the $\mathrm{LP}_{12}$ mode and a difference larger than 0.3 of $\mathrm{P}_{\mathrm{CDC}}$ between the $\mathrm{LP}_{02}$ mode and the other LOMs was taken as 
sufficient to consider this to be effective single-mode operation [37-38]. It is important to note that, the bending loss curves are fairly step, therefore there was no considerable gain in core diameter even if we would have chosen a criterion of $1 \mathrm{~dB} / \mathrm{m}$ loss for the $\mathrm{LP}_{12}$ mode. Other than the loss, the difference between the effective indices of both modes, $\mathrm{LP}_{02}$ and $\mathrm{LP}_{12}$, is also an important factor to ensure good beam quality. The higher effective refractive index difference decreases the mode coupling possibility and favors the unperturbed propagation of the $\mathrm{LP}_{02}$ mode. Moreover, HOMs are more immune to bendinduced perturbation such as coupling and distortion than the $\mathrm{LP}_{01}$ mode [39].
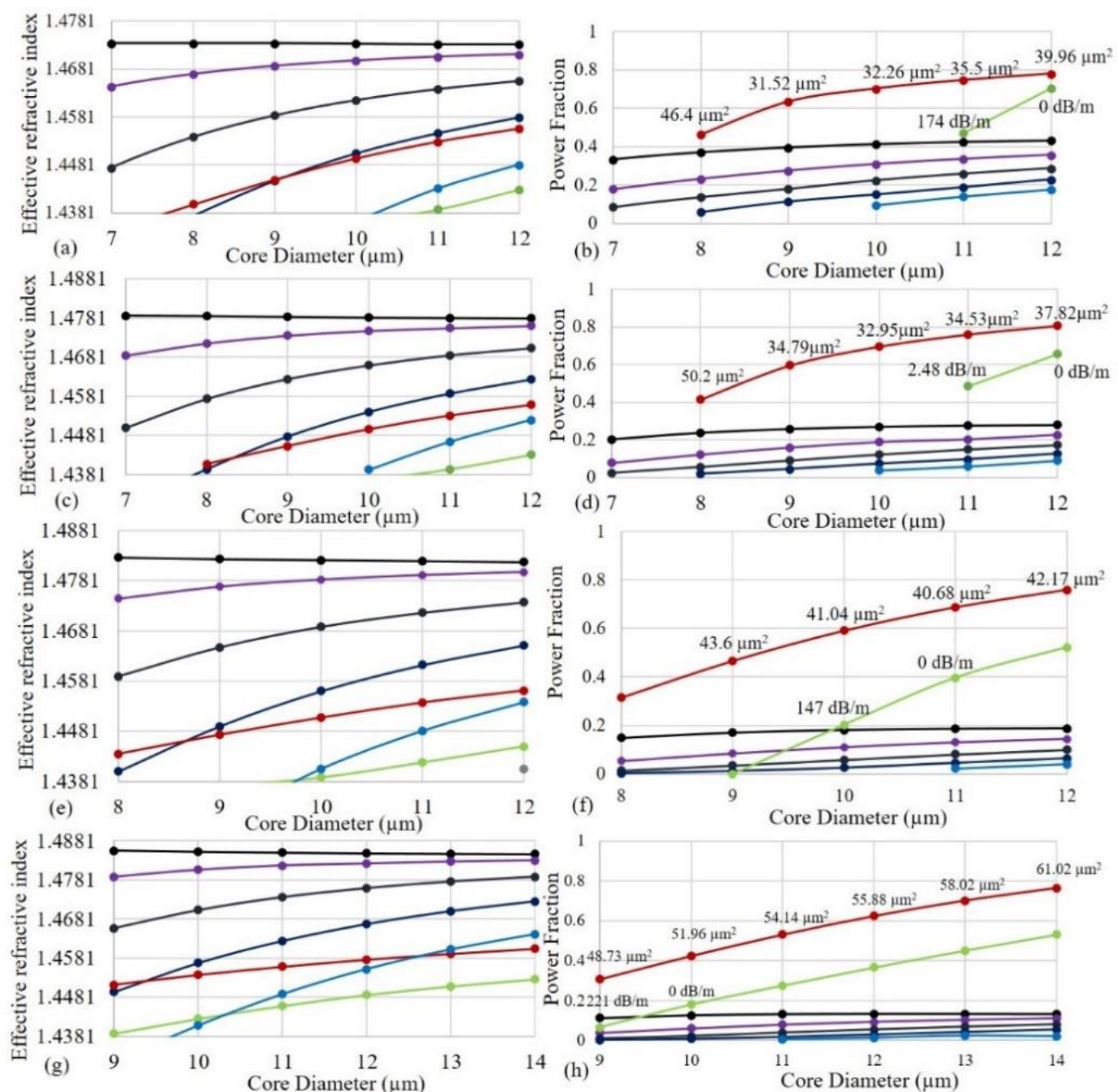

$\rightarrow$ LP01 $\rightarrow$ LP11 $\rightarrow-$ LP21 $\rightarrow$ LP31 $\rightarrow$ LP02 $\rightarrow$ LP12 $\rightarrow$ LP4

Figure 4. The dispersion profile and power fraction in central doped core $\left(\mathrm{P}_{\mathrm{CDC}}\right)$ of different modes for different core diameters and ring thicknesses $((\mathrm{a}-\mathrm{b}) \mathrm{t}=1.5$ $\mu \mathrm{m}$, (c-d) $\mathrm{t}=2 \mu \mathrm{m}$, (e-f) $\mathrm{t}=2.5 \mu \mathrm{m}$, and $(\mathrm{g}-\mathrm{h}) \mathrm{t}=3 \mu \mathrm{m}$.), for M-type fibers at $2 \mu \mathrm{m}$ operation wavelength, $5 \mathrm{~cm}$ bend diameter, $\mathrm{DN}=0.06$, and $\mathrm{Dn}=0.03$.

The ring thickness has been studied for four different values $\mathrm{t}=1.5 \mu \mathrm{m}$ (Fig. 4(a-b)), $2 \mu \mathrm{m}$ (Fig. 4(c-d), $2.5 \mu \mathrm{m}$ (Fig. 4(e-f), and $3 \mu \mathrm{m}$ (Fig. 4(g-h)). Figure 4(b) shows the absence of the $\mathrm{LP}_{12}$ mode for core diameters smaller than $11 \mu \mathrm{m}$. For larger core diameters, it is initially highly leaky $(\sim 174 \mathrm{~dB} / \mathrm{m})$ and crosses the $1 \mathrm{~dB} / \mathrm{m}$ cut-off at $11.192 \mu \mathrm{m}$, becoming a wellguided mode at $12 \mu \mathrm{m}$. Moreover, the effective refractive index difference between the $\mathrm{LP}_{02}$ and $\mathrm{LP}_{12}$ mode is $\sim 0.0142$. Therefore, the fiber is effectively single-mode for core diameter smaller than $11.19 \mu \mathrm{m}$ with an effective area of $36.27 \mu \mathrm{m}^{2}$. However, if one wants a much higher suppression of the $\mathrm{LP}_{12}$ mode $(10 \mathrm{~dB} / \mathrm{m})$, then an $11.131 \mu \mathrm{m}$ core diameter providing a $36.02 \mu \mathrm{m}^{2} \mathrm{LP}_{02}$ effective area can be considered. The four
LOMs $\left(\mathrm{LP}_{01}, \mathrm{LP}_{11}, \mathrm{LP}_{21}\right.$, and $\left.\mathrm{LP}_{31}\right)$ and one possible $\mathrm{HOM}$ $\left(\mathrm{LP}_{41}\right)$ have much lower $\mathrm{P}_{\mathrm{CDC}}$ (a maximum of $\sim 0.43$ for $\mathrm{LP}_{01}$ ) than the $\mathrm{LP}_{02}$ mode $(\sim 0.75)$. Moreover, $\sim 75 \%$ power is confined to the central region $\left(\mathrm{P}_{\mathrm{LP} 02}(\mathrm{c})\right)$ of the $\mathrm{LP}_{02}$ mode only. The $\mathrm{P}_{\mathrm{CDC}}$ and $\mathrm{P}_{\mathrm{LP} 02}(\mathrm{c})$ do not see any significant change in their values, while moving from 11 to $11.19 \mu \mathrm{m}$.

For $\mathrm{t}=2 \mu \mathrm{m}$, again up to $11.03 \mu \mathrm{m}$ core diameter, mode operation is effectively single-moded, as the bending loss of the $\mathrm{LP}_{12}$ mode is $\sim 1 \mathrm{~dB} / \mathrm{m}$ with an $\mathrm{LP}_{02}$ effective area of $\sim 34.61$ $\mu \mathrm{m}^{2}$. Moreover, the effective refractive index difference between the $\mathrm{LP}_{02}$ and $\mathrm{LP}_{12}$ mode is $\sim 0.0137$. For $10.943 \mu \mathrm{m}$ core diameter, the bending loss of $\mathrm{LP}_{02}$ mode is $10 \mathrm{~dB} / \mathrm{m}$ with 
an effective area is $\sim 34.37 \mu \mathrm{m}^{2}$ and the $\mathrm{P}_{\mathrm{LP} 02}(\mathrm{c})$ is $\sim 0.76$. Due to the larger thickness of the high-index ring, the $\mathrm{P}_{\mathrm{CDC}}$ of all the LOMs and one possible HOM $\left(\mathrm{LP}_{41}\right)$ is lower than 0.28 , while it is more than 0.76 for the $\mathrm{LP}_{02}$ mode, achieving a difference of $\sim 0.48 \mathrm{P}_{\mathrm{CDC}}$. For $\mathrm{t}=2.5 \mu \mathrm{m}$, at a core diameter of $10.27 \mu \mathrm{m}$ the $\mathrm{LP}_{12}$ mode reaches a level of $1 \mathrm{~dB} / \mathrm{m}$ bending loss with an $\mathrm{LP}_{02}$ effective area of $\sim 40.74 \mu \mathrm{m}^{2}$. The same reaches a level of 10

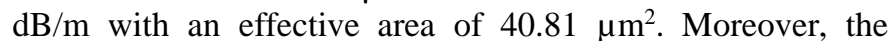
effective refractive index difference between the $\mathrm{LP}_{02}$ and $\mathrm{LP}_{12}$ mode is $\sim 0.012$. The $\mathrm{P}_{\mathrm{LP} 02}(\mathrm{c})$ is $\sim 0.63$. The $\mathrm{P}_{\mathrm{CDC}}$ for the $\mathrm{LP}_{02}$ mode is $\sim 0.59$, while the same for all LOMs and one possible $\operatorname{HOM}\left(\mathrm{LP}_{41}\right)$ is lower than 0.20 . For $\mathrm{t}=3 \mu \mathrm{m}$, at a core diameter of $\sim 9.2 \mu \mathrm{m}$ the $\mathrm{LP}_{12}$ mode reaches a threshold of $1 \mathrm{~dB} / \mathrm{m}$ bending losses with an $\mathrm{LP}_{02}$ effective area of $\sim 49.5 \mu \mathrm{m}^{2}$. The $\mathrm{P}_{\mathrm{LP} 02}(\mathrm{c})$ is $\sim 0.49$, with a poor $\sim 0.33 \mathrm{P}_{\mathrm{CDC}}$, while the $\mathrm{P}_{\mathrm{CDCs}}$ for the LOMs are less than 0.13 . It is interesting to note that, with increasing t, the $\mathrm{LP}_{02}$ mode profile evolves towards a flat field, this leads to the poor overlap with the doped region and nearly equal or greater power in the annular region. Therefore, for the proposed application, it is beneficial to confine the thickness of the high-index ring to be between 1.5 to $2.5 \mu \mathrm{m}$.

In summary, for $\mathrm{DN}=0.06$ and $\mathrm{Dn}=0.03, \mathrm{t}=1.5$ to $2.5 \mu \mathrm{m}, \mathrm{a} \mathrm{PP}_{02}$ mode with an effective area from 34.4 to $40.8 \mu \mathrm{m}^{2}$, a $\mathrm{P}_{\mathrm{LP} 02}(\mathrm{c})$ from 0.63 to 0.76 , a minimum effective refractive index difference of $\sim 0.012$ between the $\mathrm{LP}_{02}$ and $\mathrm{LP}_{12}$ modes, and a minimum of $\sim 0.32 \mathrm{P}_{\mathrm{CDC}}$ difference between the $\mathrm{LP}_{02}$ mode and any other possible LOMs or HOMs can be achieved while ensuring a minimum loss of $10 \mathrm{~dB} / \mathrm{m}$ for the $\mathrm{LP}_{12}$ mode.
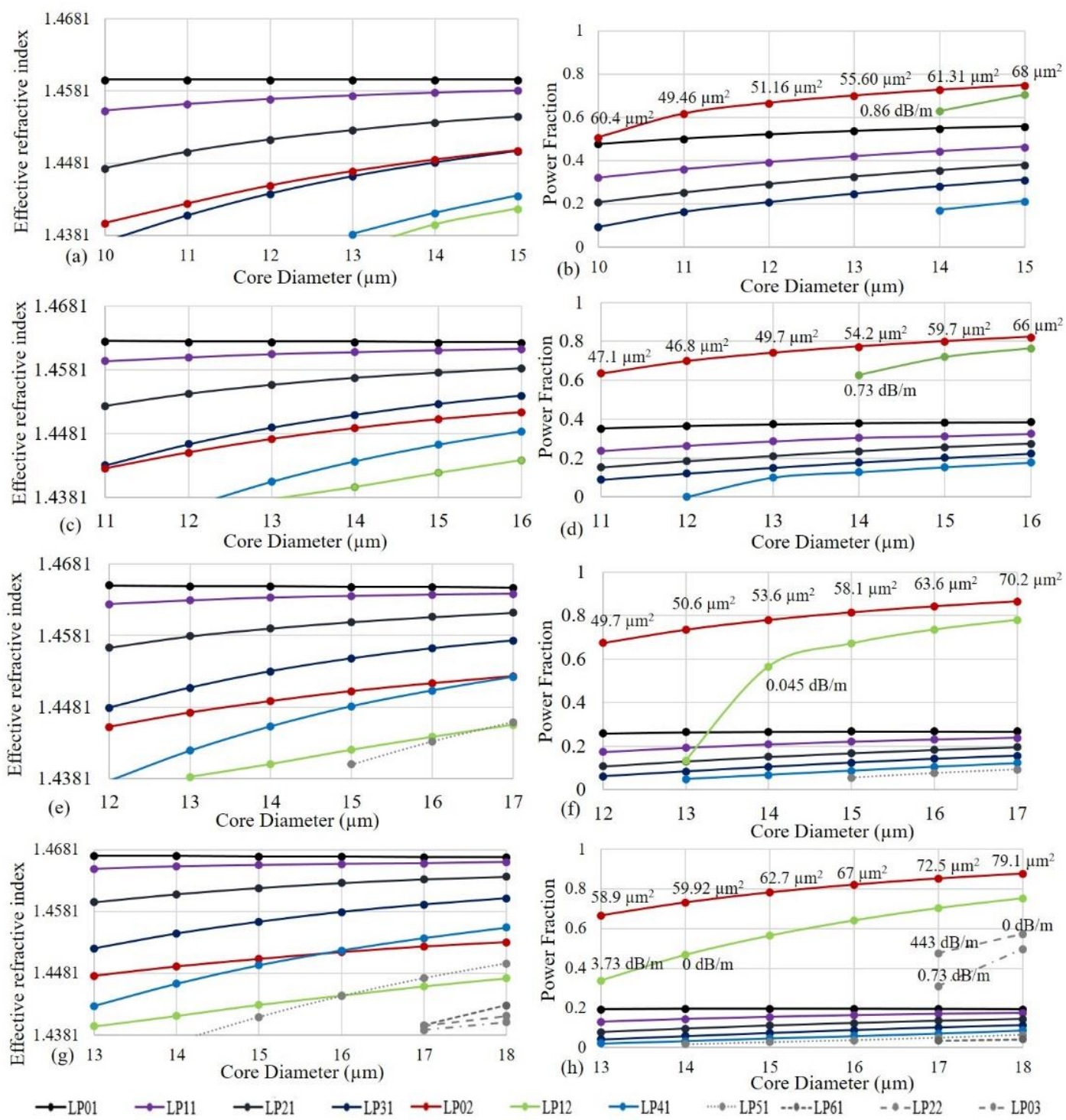

Figure 5. The dispersion profile and power fraction in central doped core $\left(\mathrm{P}_{\mathrm{CDC}}\right)$ of different modes for different core diameters and ring thicknesses $((\mathrm{a}-\mathrm{b}) \mathrm{t}=1.5$ $\mu \mathrm{m}$, (c-d) $\mathrm{t}=2 \mu \mathrm{m}$, (e-f) $\mathrm{t}=2.5 \mu \mathrm{m}$, and $(\mathrm{g}-\mathrm{h}) \mathrm{t}=3 \mu \mathrm{m})$ for M-type fibers at $2 \mu \mathrm{m}$ operation wavelength, $5 \mathrm{~cm}$ bend diameter, DN=0.04, and Dn=0.02.

\section{b) $\mathrm{DN}=0.04$ and $\mathrm{Dn}=0.02$}

Figure 5 shows the dispersion profiles of the different modes and $\mathrm{P}_{\mathrm{CDC}}$ for varying core diameters for fixed $\mathrm{DN}=0.04$,
$\mathrm{Dn}=0.02, \lambda=2 \mu \mathrm{m}$, and coiled at a bend diameter of $5 \mathrm{~cm}$. The ring thickness has been again studied for four different values $\mathrm{t}=1.5 \mu \mathrm{m}$ (Fig. 5(a-b)), $2 \mu \mathrm{m}$ (Fig. 5(c-d)), $2.5 \mu \mathrm{m}$ (Fig. 5(e-f), and $3 \mu \mathrm{m}$ (Fig. $5(\mathrm{~g}-\mathrm{h})$ ). For $\mathrm{t}=1.5 \mu \mathrm{m}$, at a core diameter of 
$\sim 13.99 \mu \mathrm{m}$ the $\mathrm{LP}_{12}$ mode reaches a threshold of $1 \mathrm{~dB} / \mathrm{m}$ bending losses with an $\mathrm{LP}_{02}$ effective area of $\sim 61.3 \mu \mathrm{m}^{2}$ and a 0.009 difference between the $\mathrm{LP}_{02}$ and $\mathrm{LP}_{12}$ modes. The $\mathrm{P}_{\mathrm{LP0} 2}(\mathrm{c})$ is $\sim 0.71$ along with $\sim 0.73 \mathrm{P}_{\mathrm{CDC}}$. However, due to small thickness of the high-index ring, a high $\sim 0.55 \mathrm{P}_{\mathrm{CDC}}$ exists for all possible LOMs and one possible HOM $\left(\mathrm{LP}_{41}\right)$. Moving to $\mathrm{t}=2$ $\mu \mathrm{m}$, slightly changes the threshold for 1 and $10 \mathrm{~dB} / \mathrm{m}$ bending losses of the $\mathrm{LP}_{12}$ mode to $\sim 13.98$ and $\sim 13.85 \mu \mathrm{m}$ core diameter with an $\mathrm{LP}_{02}$ effective area of $\sim 54.2$ and $\sim 53.41 \mu \mathrm{m}^{2}$ and a 0.0084 difference between the $\mathrm{LP}_{02}$ and $\mathrm{LP}_{12}$ modes. The $\mathrm{P}_{\mathrm{LP02} 2}(\mathrm{c})$ is $\sim 0.77$ along with $\sim 0.77 \mathrm{P}_{\mathrm{CDC}}$, while ensuring a low $\sim 0.38 \mathrm{P}_{\mathrm{CDC}}$ for all possible LOMs and one possible HOM $\left(\mathrm{LP}_{41}\right)$.

For $\mathrm{t}=2.5 \mu \mathrm{m}$, the threshold of 1 and $10 \mathrm{~dB} / \mathrm{m}$ bending losses of the $\mathrm{LP}_{12}$ mode moves to $\sim 13.75$ and $\sim 13.60 \mu \mathrm{m}$ core diameter with an $\mathrm{LP}_{02}$ effective area of $\sim 52.7$ and $\sim 52.2 \mu \mathrm{m}^{2}$ and a 0.0081 difference between the $\mathrm{LP}_{02}$ and $\mathrm{LP}_{12}$ modes. The $\mathrm{P}_{\mathrm{LP} 02}(\mathrm{c})$ is $\sim 0.77$ along with $\sim 0.77 \mathrm{P}_{\mathrm{CDC}}$, while ensuring a low $\sim 0.27 \mathrm{P}_{\mathrm{CDC}}$ for all possible LOMs and one possible HOM $\left(\mathrm{LP}_{41}\right)$. For $\mathrm{t}=3$ $\mu \mathrm{m}$, the threshold of 1 and $10 \mathrm{~dB} / \mathrm{m}$ bending losses of the $\mathrm{LP}_{12}$ mode moves to $\sim 13.08$ and $\sim 12.91 \mu \mathrm{m}$ core diameter with an $\mathrm{LP}_{02}$ effective area of $\sim 58.92$ and $\sim 58.90 \mu \mathrm{m}^{2}$ and a 0.0083 refractive index difference between the $\mathrm{LP}_{02}$ and $\mathrm{LP}_{12}$ modes. The $\mathrm{P}_{\mathrm{LP} 02}(\mathrm{c})$ is $\sim 0.69$ along with $\sim 0.67 \mathrm{P}_{\mathrm{CDC}}$, while ensuring a low $\sim 0.2 \mathrm{P}_{\mathrm{CDC}}$ for all possible LOMs and one possible HOM $\left(\mathrm{LP}_{41}\right)$.

In summary, for $\mathrm{DN}=0.04$ and $\mathrm{Dn}=0.02, \mathrm{t}=2 \mu \mathrm{m}$ to $3 \mu \mathrm{m}$, a $\mathrm{LP}_{02}$ mode with an effective area from $\sim 52.2$ to $58.9 \mu \mathrm{m}^{2}$, a $\mathrm{P}_{\mathrm{LP} 02}(\mathrm{c})$ from 0.69 to 0.77 , a minimum effective refractive index difference of $\sim 0.0083$ between the $\mathrm{LP}_{02}$ and $\mathrm{LP}_{12}$ modes, and a minimum of $\sim 0.39 \mathrm{P}_{\mathrm{CDC}}$ difference between the $\mathrm{LP}_{02}$ mode and any other possible LOMs or HOMs, can be achieved while ensuring a minimum loss of $10 \mathrm{~dB} / \mathrm{m}$ for the $\mathrm{LP}_{12}$ mode.

\section{COMPARISON WITH STEP INDEX FIBER}

In order to validate the importance of the use of the $\mathrm{LP}_{02}$ mode in High-NA M-type fiber, it is important to compare their performance with SIFs. Figure 6 shows the effective refractive indices of the $\mathrm{LP}_{01}$ and $\mathrm{LP}_{11}$ modes with respect to the core diameters for different refractive index between core and cladding $(\triangle \mathrm{n})$ (see Fig. 6(a) for 0.03 and Fig. 6(b) for 0.02). The effective area for the $\mathrm{LP}_{01}$ mode and bending loss for the $\mathrm{LP}_{11}$ mode coiled at $5 \mathrm{~cm}$ bend diameter are also shown in the figure. The same criterion of $10 \mathrm{~dB} / \mathrm{m}$ bending loss for the $\mathrm{LP}_{11}$ mode is considered sufficient to suppress the mode for SIFs. Figure 6(a) shows that for $\Delta \mathrm{n}=0.03$, a core diameter of 5.535 $\mu \mathrm{m}$ offers a bending loss of $10 \mathrm{~dB} / \mathrm{m}$ to the $\mathrm{LP}_{11}$ mode at $5 \mathrm{~cm}$ coiling diameter while achieving an $\mathrm{LP}_{01}$ effective area of $\sim 26.62 \mu \mathrm{m}^{2}$. Similarly following the same criterion, for $\triangle \mathrm{n}=0.02$, a core diameter of $6.976 \mu \mathrm{m}$ with an $\mathrm{LP}_{01}$ effective area of $\sim 41.02 \mu \mathrm{m}^{2}$ can be achieved.
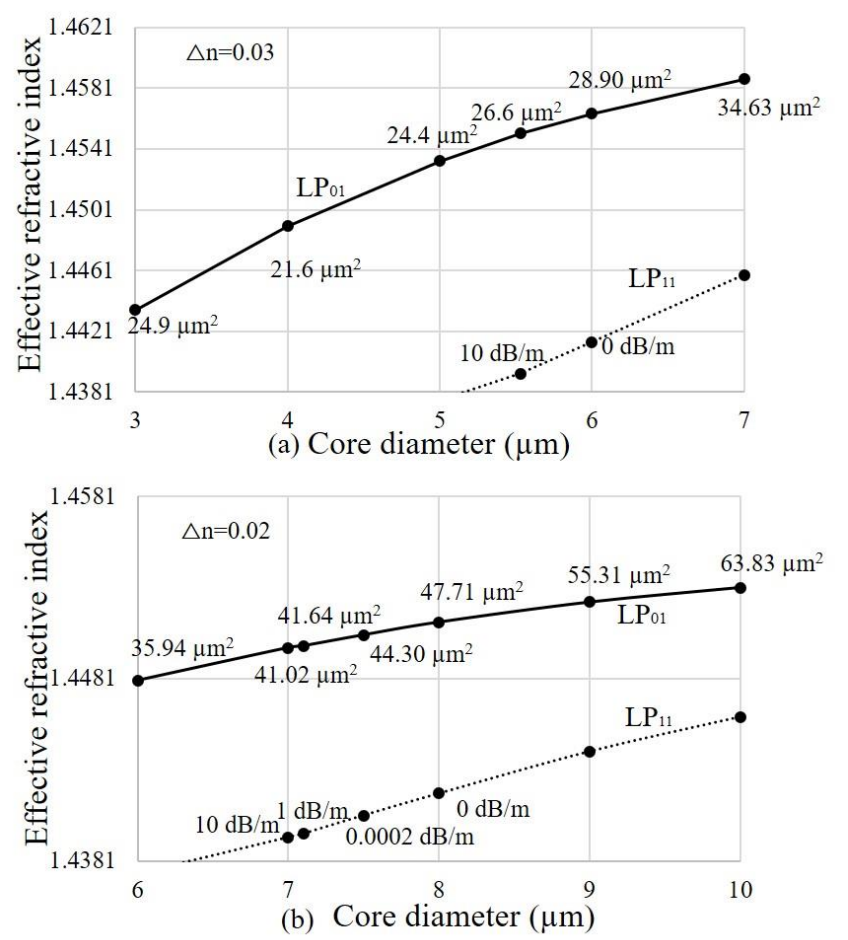

Figure 6. The effective refractive indices of the $\mathrm{LP}_{01}$ and $\mathrm{LP}_{11}$ modes with effective areas of the $\mathrm{LP}_{01}$ mode and the bend losses of the $\mathrm{LP}_{11}$ mode coiled at $5 \mathrm{~cm}$ bend diameter for different core diameters: (a) $\triangle \mathrm{n}=0.03$ and (b) $\triangle \mathrm{n}=0.02$.

Figure 7 shows the comparative analysis of the SIF and M-type fibers at two different coiling diameters $5 \mathrm{am}$ and $10 \mathrm{~cm}$. A coiling of $5 \mathrm{~cm}$ can lead to the mechanical failure of the fiber while running very high power through it, therefore a larger diameter such as $10 \mathrm{~cm}$ can be worth exploring. Again, for 10 $\mathrm{cm}$, a criterion of $10 \mathrm{~dB} / \mathrm{m}$ loss for $\mathrm{LP}_{11}$ has been used. For the case of 0.03 Dn or $\triangle \mathrm{n}$, a gain of $\sim 29$ to $\sim 57 \%$ in $\mathrm{LP}_{01}$ effective area is apparent, of course with larger doped cores. Similarly, for $0.02 \mathrm{Dn}$ or $\Delta \mathrm{n}$, there is nearly $\sim 27$ to $49 \%$ gain in $\mathrm{LP}_{01}$ effective area with large doped cores. The larger doped core increases the pumped absorption in both core and cladding pump configuration. This can be very helpful in increasing efficiency and power scaling of the output signal. For both cases of Dn, $\Delta n=0.03$ and Dn, $\Delta n=0.02$, the area of the doped core of the M-type is larger than the SIF by 50 to $100 \%$. Therefore, these M-type fibers offer dual benefits by offering higher effective area in larger core diameters. It is important to note that the gain in effective area ( $27 \%$ to $57 \%)$ is much smaller than that achieved for mode area scaling using other fiber designs reported in the introduction at $1 \mu \mathrm{m}$ operational wavelength for $\mathrm{Yb}$-doped fiber lasers. However, as stated in introduction, these fiber designs require nearly the same refractive index for core and cladding, therefore they cannot allow high refractive index difference between core and cladding such as 0.02 and 0.03 [40]. Maintaining single-mode operation for high refractive index difference between core and cladding, such as 0.02 and 0.03 , is a significant challenge. To 


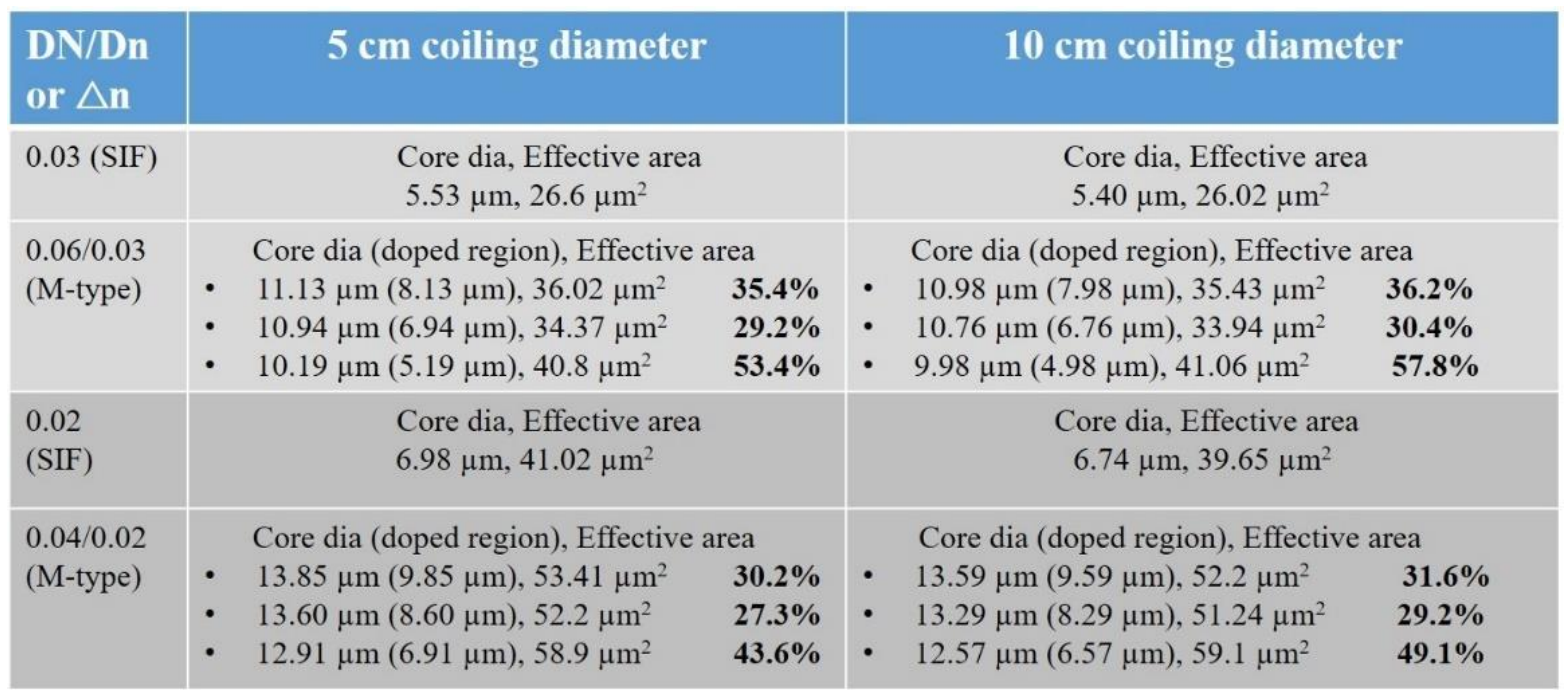

Figure 7. A comparative analysis of the SIF and M-type fibers for the same $\Delta \mathrm{n}$ and $\mathrm{Dn}$ at two different coiling diameters $5 \mathrm{~cm}$ and $10 \mathrm{~cm}$. The bold letters show the percentage increases in effective area for a particular case.

the best of, our knowledge, this is the first numerical demonstration of breaking the trade-off between effective single mode operation and higher NAs without using the cumbersome technique of conversion of the $\mathrm{LP}_{01}$ mode to the $\mathrm{LP}_{0 \mathrm{x}}$ mode and re-conversion of the $\mathrm{LP}_{0 \mathrm{x}}$ mode to the $\mathrm{LP}_{01}$ mode.

\section{FEASIBILITY OF M-TYPE FIBERS}

The proposed M-type fibers can be fabricated using modified chemical vapour deposition (MCVD) process in conjunction with solution doping process. It is also important to mention that, passive fibers similar but more complicated than the Mtype fibers have been successfully fabricated using MCVD process [31-33]. The active version of these fibers with confined doping of $\mathrm{Yb}^{3+}$ and co-dopants ions in central core have been fabricated using rod-in-tube technique [34]. An $\mathrm{Yb}^{3+}$ and co-doped preform was fabricated either using solution doping or vapour phase deposition and was further jacketed inside a silica tube having high-index layers deposited using chemical vapour deposition [34]. Aleshkina et al. used the rodin-tube technique, possibly their design is much more complicated having two high-index layers and one absorbing layer [34]. For our case, we have only one high-index layer, therefore it can be easily fabricated using solution-doping during MCVD process. In nutshell, the proposed fiber design is possible to fabricate using current-state-of-the-art fabrication technology. A non-circular cladding can be used in order to avoid the coherent reflection from cladding to polymer interface back to the core for the leaky $\mathrm{LP}_{12}$ mode [34, 41-42]. This will increase the cladding pump absorption as well.

A standard step-index fiber can be spliced to the proposed Mtype fiber for excitation of the $\mathrm{LP}_{02}$ mode. The parameters of SIF (D and NA) can be optimized for a given M-type fiber with $\mathrm{D}, \mathrm{t}, \mathrm{DN}$, and Dn to match the field profiles of the $\mathrm{LP}_{01}$ (of SIF) and $\mathrm{LP}_{02}$ (of M-type fiber) modes. Aleshkina et al. successfully launched the $\mathrm{LP}_{02}$ mode by splicing a single-mode fiber to their hybrid fiber, despite not using optimum parameter, splice losses lower than $1 \mathrm{~dB}$ to $1.5 \mathrm{~dB}$ were achieved from $\sim 0.9 \mu \mathrm{m}$ to $\sim 1.064 \mu \mathrm{m}$ wavelengths respectively [31]. It is important to note that, the work reported by Aleshkina et al. in [32-34] deals with the $\mathrm{LP}_{03}$ mode in complicated fiber than the $\mathrm{LP}_{02}$ mode in a simpler fiber [31]. Our design should be compared with work reported in [31] only, as we exploit only the $\mathrm{LP}_{02}$ mode and use only one high-index ring.

It is likely that despite using optimum parameters, the LOMs may get excited in the high-index ring, though with low power ( 5 to $20 \%$ ) content in total. This is where, confined doping plays its role. A power fraction difference of more than 0.3 with the doped region between the fundamental mode and other higherorder modes is enough to ensure an effective single-mode operation [37]. Moreover, just confined doping technique has been used in SIFs for suppressing the HOMs [43-44]. Moreover, it is also not necessary to dope the whole depressedindex core, if required for higher suppression of the HOMs, then the depressed core only be partially doped.

\section{CONCLUSION}

The exploitation of the $\mathrm{LP}_{02}$ mode in ultra-high NA M-type fibers has been investigated for mode-area scaling applications. Numerical simulations demonstrate the feasibility of effective single-mode operation for with effective areas ranging from $\sim 34 \mu \mathrm{m}^{2}$ to $\sim 59 \mu \mathrm{m}^{2}$ for different Dn, such as 0.02 to 0.03 , at 2 $\mu \mathrm{m}$ wavelength, for small coil diameters such as 5 to $10 \mathrm{~cm}$. These effective areas represent a 27 to $57 \%$ increment with respect to current state-of-the-art SIFs. These high Dn would allow the required doping levels of $\mathrm{Tm}^{3+}$ and $\mathrm{Al}^{3+}$ ions for efficient 2-for-1 cross-relaxation process leading to high slope efficiency for $2 \mu \mathrm{m}$ lasing, when pumped at $793 \mathrm{~nm}$.

\section{REFERENCES}

1. G. Agrawal, "Nonlinear Fiber Optics," $5^{\text {th }}$ Ed. (Academic, 2012).

2. A. W. Snyder and J. D. Love, "Optical Waveguide Theory", (Kluwer Academic, 1983).

3. D. Jain, Y. Jung, P. Barua, S. Alam, and J. K. Sahu, "Demonstration of ultra-low NA step index fiber for applications in high power fiber laser," Opt. Exp., vol. 23, no. 6, pp. 7407-7415, March 2015. 
4. E. M. Dianov, M. E. Likhachev, and S. Fevrier, "Solid-core photonic bandgap fibers for high-power fiber lasers," IEEE J. Sel. Top. Quantum Electron., vol. 15, no. 1, pp. 20-29, Jan. 2009.

5. $\quad$ G. Gu, F. Kong, T. W. Hawkins, M. Jones, and L. Dong, "Extending mode areas of single-mode all-solid photonic bandgap fibers," Opt. Exp., vol 23, no. 7, pp. 9147-9156, April 2015.

6. D. Jain, C. Baskiotis, J. Kim, and J. K. Sahu, "First demonstration of singletrench fiber laser," SF1N.1 in Conference on Lasers and Electro-Optics, OSA Technical Digest (online) (Optical Society of America) (Invited) San Jose, USA, June 2014.

7. D. Jain et al., "High power, compact, picosecond MOPA based on single trench fiber with single polarized diffraction-limited output," Opt. Lett., vol. 40, no. 17, pp. 4150-4153, Aug. 2015.

8. D. Jain et al., "Highly efficient Yb-free Er-La-Al doped ultra-low NA large mode area single-trench fiber laser," Opt. Exp., vol. 23, no. 22, pp. 28282-28287, Oct. 2015.

9. X. Ma, C. Zhu, I-Ning Hu, A. Kaplan, and A. Galvanauskas, "Singlemode chirally-coupled-core fibers with larger than $50 \mu \mathrm{m}$ diameter cores," Opt. Exp., vol. 22, no. 8, pp. 9206-9219, April 2014.

10. J. Limpert, F. Stutzki, F. Jansen, H. J. Otto, T. Eidam, C. Jauregui, and A. Tunnermann, "Yb-doped large-pitch fibers: effective single-mode operation based on higher-order mode delocalization", Light: Sci. \& App. vol. 1, pp. 1-5, March 2012.

11. D. Jain, C. Baskiotis, and J. K. Sahu, "Mode-area scaling with multitrench rod type fiber," Opt. Exp., vol. 21, no. 2, pp. 1448-1455, Jan 2013.

12. S. D. Jackson, "Cross relaxation and energy transfer upconversion processes relevant to the functioning of $2 \mu \mathrm{m} \mathrm{Tm} 3+$-doped silica fibre lasers," Opt. Commun., vol. 230, no. 1-3, pp. 197-203, Jan. 2004.

13. P. C. Shardlow, D. Jain, R. Parker, J. Sahu, and W. A. Clarkson, "Optimising Tm-doped silica sibres for high lasing efficiency," in European Conference on Lasers and Electro-Optics - European Quantum Electronics Conference, (Optical Society of America, 2015), paper. CJ_14_13.

14. N. J. Ramirez-Martinnez, M. Nunez-Velazquez, A. A. Umnikov, and J. K. Sahu, "Highly efficient thulium-doped high-power laser fibers fabricated by MCVD," Opt. Exp., vol. 27, no. 1, pp. 196-201, Jan. 2019.

15. R. Tumminelli, V. Petit, A Carter, A Hemming, N Simkaov, and J. Haub, "Highly doped and highly efficient Tm doped fiber laser," (conference presentation) Photonics West, 105120M, March 2018.

16. A. Sincore, J. D. Bradford, J. Cook, L. Shah, and M. C. Richardson, "High Average Power Thulium-Doped Silica Fiber Lasers: Review of Systems and Concepts," IEEE J. of Sel. Top. In Quant. Electron., vol. 24, no. 3, 0901808, June 2018.

17. S. Ramachandran, J. M. Fini, M. Mermelstein, J. W. Nicholson, S. Ghalmi, and M. F. Yan, "Ultra-large effective-area, higher-order mode fibers: a new strategy for high-power lasers," Lasers \& Photon Rev., vol. 2, no. 6, pp. 429-448, Dec. 2008.

18. K. Tankala, B. Samson, A. Carter, J. Farroni, D. Machewirth, N. Jacobson, U. Manyam, A. Sanchez, M-Y. Cheng, A. Galvanauskas, W. Torruellas and Y. Chen, "New Developments in High Power Eye-Safe LMA Fibers," Proc. SPIE 6102, Fiber Lasers III: Technology, Systems, and Applications, 610206 (2006).

19. J.W. Nicholson et al., "Axicons for mode conversion in high peak power, higher-order mode, fiber amplifier," Opt. Exp., vol. 23, no. 6, pp. 3384933860, Dec. 2015.

20. N. Simakov et al., "Design and experimental demonstration of a large pedestal thulium-doped fibre," Opt. Exp., vol. 23, no. 3, pp. 3126-3133, Feb. 2015.

21. T. Walbaum, M. Heinzig, T. Schreiber, R. Eberhardt, and A. Tunnermann, "Monolithic thulium fiber laser with $567 \mathrm{~W}$ output power at $1970 \mathrm{~nm}$," Opt. Lett., vol. 41, no. 11, pp. 2632-2635, May 2016.

22. C. Jollivet, K. Farley, M. Conroy, H. Dabhi, J.Edgecumbe, A. Carter and K. Tankala, "Design optimization of Tm-doped large-mode area fibers for power scaling of $2 \mu \mathrm{m}$ lasers and amplifiers," Proc. SPIE 10083, Fiber Lasers XIV: Technology and Systems, 100830I (2017).

23. A. Hemming, N. Simakov, K. Boyd, R. Swain, E. Mies, A. Davidson, N. Carmody, K. Farley, J. Haub and A. Carter "Power scaling of singlemode, high power thulium-doped fibre lasers," (conference presentation) Photonics West, 10897-6, Feb 2019.

24. V. Kuhn et al., "Experimental Comparison of Fundamental Mode Content in Er:Yb-Codoped LMA Fibers With Multifilament- and Pedestal-Design Cores," Journal of Lightwav Techno., vol. 28, no. 22, pp. 3212-3219, Nov. 2010.

25. P. Glas, M. Naumann, A. Schirrmacher, S. Unger, and T. Pertsch, "Shortlength 10-W cw neodymium-doped M-profile fiber laser," Appl. Optics vol. 37, no. 36, pp. 8434-8437, Dec. 1998.

26. I. V. Neves and A. S. C. Fernandes, "Modal characteristics for W-type and M-type dielectric profile fibers," Microwave and Opt. Techno. Lett., vol. 22, no. 6, pp. 398-405, Sept. 1999.

27. M. Hautakorpi and M. Kaivola, "Modal analysis of M-type-dielectricprofile optical fibers in the weakly guiding approximation," J. Opt. Soc. Am. B, vol 22, no. 6, pp. 1163-1169, June 2005 .

28. A. K. Ghatak, I. C. Goyal, and R. Jindal, "Design of a waveguide refractive index profile to obtain a flat model field," Proc. of SPIE, 3666, pp. 40-44, April 1999.

29. J. W. Dawson et al., "Large flattened mode optical fiber for reduction of non-linear effects in optical fiber lasers," Proc. of SPIE, 5335, pp. 132139, June 2004

30. C. Valentin et al., "Top-hat beam output of a single-mode microstructured optical fiber: impact of core index depression," Opt. Exp., vol. 21, no. 20, pp. 23250-23260, Sept. 2013.

31. S. S. Aleshkina et al., "Low-loss hybrid fiber with zero dispersion wavelength shifted to $1 \mu \mathrm{m}$," Opt. Exp., vol. 21, no. 20, pp. 23838-23843, Sept. 2013.

32. S. S. Aleshkina, "Quasi-single-mode hybrid fibre with anomalous dispersion in the $1 \mathrm{~nm}$ range." Quantum Electronics, vol. 46, no. 8, pp.738-742 (2016).

33. S. S. Aleshkina, M. V. Yashkov, M M. Bubnov, A. N. Guryanov, and M. E. Likhachev "Asymptotically single-mode hybrid fiber for dispersion management near $1 \mu \mathrm{m}$." IEEE J. of Sel. Top. In Quant. Electron. Vol. 24, no. 3, 0901608, June 2018.

34. S. S. Aleshkina et al., "High-Peak-Power Femtosecond Pulse Generation by Nonlinear Compression in a Yb-Doped Hybrid Fiber," IEEE Photonics, vol. 11, no. 5, 7103411, Oct. 2019.

35. D. Jain, C. Markos, T. M. Benson, A. B. Seddon, and O. Bang, "M-type fiber for exploiting higher-order-modes' anomalous dispersion for application in supercontinuum generation" Nature: Scientific Reports 9, 8536, June 2019.

36. Y. Chen, Z. Chen, W. J. Wadsworth, and T. A. Birks, "Nonlinear optics in the $\mathrm{LP}_{02}$ higher-order mode of a fiber," Optics Express, vol. 21, no. 15, pp. 17786-17799, July 2013.

37. C. Molardi, F. Poli, L. Rosa, S. Selleri, and A. Cucinotta, "Mode discrimination criterion for effective differential amplification in Ybdoped fiber design for high power operation," Opt. Exp., vol 25, no. 13, pp. 29013-29025, Nov. 2017.

38. D. Jain, Y. Jung, M. N. Velazquez, and J. K. Sahu, "Extending single mode performance of all-solid large-mode-area single trench fiber," Opt. Exp., vol 22, no. 25, pp. 31078-31091, Dec. 2014.

39. J. M. Fini and Siddharth Ramachandaran, "Natural bend-distortion immunity of higher-order-mode large-mode-area fibers," Optics Letter, vol. 32, no. 7, pp. 748-750 2007.

40. D. Jain and J. K. Sahu, "Performance of single-trench fiber at $2 \mu \mathrm{m}$," Journal of Lightwave Technology, vol 34, no. 14, pp. 3412-3417, July 2016.

41. G. Gu, F. Kong, T. W. Hawkins, P. Foy, K. Wei, B. Samson, and L. Dong, "Impact of fiber outer boundaries on leaky mode losses in leakage channel fibers," Opt. Express 21(20), 24039-24048 (2013).

42. D. Jain, "Novel optical fibers for high power lasers" Page 7, Chapter 1, PhD Thesis, University of Southampton, UK (2015).

43. J. R. Marciante, R. G. Roides, V. V. Shkunov, and D. A. Rockwel, "Neardiffraction-limited operation of step-index large-mode-area fiber lasers via gain filtering," Opt. Lett. 35(11), 1828-1830 (2010).

44. S. Gausmann, J. E. Antonio-Lopez, J. Anderson, S. Wittek, S. E. Eznaveh, Hee-Jun Jang, Md S Habib, J Cook, M. C. Richardson, R. A. Correa, and A. Schülzgen, " $\mathrm{S}^{2}$ measurements showing suppression of Higher Order Modes in Confined Rare Earth Doped Large Core Fibers," Journal of Lightwave Technology, vol 38, no. 7, pp. 1953-1958, April 2020. 